\title{
Hypoxia-induced Tie1 drives stemness and cisplatin resistance in non-small cell lung carcinoma cells
}

\author{
Chaojie Li ${ }^{1 \dagger}$, Nannan Yang ${ }^{1 \dagger}$, Zhijin Chen ${ }^{1 \dagger}$, Ning Xia ${ }^{1}$, Qungang Shan ${ }^{1}$, Ziyin Wang ${ }^{1}$, Jian Lu' ${ }^{1}$, Mingyi Shang ${ }^{2 *}$ \\ and Zhongmin Wang ${ }^{1,3^{*}}$ (D)
}

\begin{abstract}
Background: Drug resistance and metastasis involving hypoxic tumor environments and persistent stem cell populations are detrimental to the survival of patients with non-small cell lung carcinoma (NSCLC). Tie1 is upregulated in hypoxia and is believed to counteract the effectiveness of platinum agents by promoting the stemness properties in cells. We have investigated the association of Tie1 with HIF-1a and cisplatin resistance in NSCLC cell lines.

Methods: The expression of Tie1 in a pulmonary microvascular endothelial cell line (HPMEC) and NSCLC cell lines was detected using qRT-PCR and western blotting. The effect of Tie 1 on cell stemness and migration was examined by sphere-forming and transwell assays in NSCLC cells with Tie1 silenced. The regulation of Tie1 by HIF-1a was evaluated by a dual-luciferase reporter assay and chromatin immunoprecipitation.

Results: We found that hypoxia could induce stemness and cisplatin resistance in vitro. Tie1 was expressed at low levels in NSCLC cells when compared with human pulmonary microvascular endothelial cells, however, its expression was increased by hypoxia. Additionally, Tie1 knockdown could reduce stemness properties and increase sensitivity to cisplatin in vitro and in a xenograft mouse model. The promoter of Tie1 contains two predicted hypoxia-response elements (HREs). We mutated both HRE sites and conducted chromatin immune-precipitation and promoter luciferase reporter assays and were able to conclude that the induction of Tie1 by hypoxia was HIF-1a-dependent.
\end{abstract}

Conclusions: Our findings indicated that Tie 1 is upregulated in a hypoxic environment by HIF-1a and contributes to tumorigenesis and cisplatin resistance through the promotion of stemness in NSCLC cells.

Keywords: Tie1, Hypoxia, Stemness, HIF-1a, Cisplatin resistance

*Correspondence: myshang1969@aliyun.com; wzm11896@rjh.com.cn ${ }^{\dagger}$ Chaojie Li, Nannan Yang and Zhijin Chen contributed equally to this work

${ }^{1}$ Department of Radiology, Ruijin Hospital Luwan Branch, Shanghai Jiao Tong University School of Medicine, No. 149 Chongqing South Road,

Shanghai 200025, China

2 Department of Interventional Radiology, Tongren Hospital,

Shanghai Jiao Tong University School of Medicine, 1111 Xianxia Road, Shanghai 200336, China

Full list of author information is available at the end of the article

\section{Background}

Although the incidence of lung cancer has decreased considerably over the last decade, it is still responsible for greater mortality than breast, colorectal, and prostate cancers combined and remains the leading cause of cancer-related deaths globally [1, 2]. The World Health Organization has classified lung cancer as either small cell or non-small cell depending on histology [3]. However, the majority of lung cancers $(85 \%)$ are nonsmall cell lung carcinoma (NSCLC) and include adenocarcinoma, squamous cell carcinoma, and large cell

(c) The Author(s) 2021. This article is licensed under a Creative Commons Attribution 4.0 International License, which permits use, sharing, adaptation, distribution and reproduction in any medium or format, as long as you give appropriate credit to the original author(s) and the source, provide a link to the Creative Commons licence, and indicate if changes were made. The images or other third party material in this article are included in the article's Creative Commons licence, unless indicated otherwise in a credit line to the material. If material is not included in the article's Creative Commons licence and your intended use is not permitted by statutory regulation or exceeds the permitted use, you will need to obtain permission directly from the copyright holder. To view a copy of this licence, visit http://creativeco mmons.org/licenses/by/4.0/. The Creative Commons Public Domain Dedication waiver (http://creativecommons.org/publicdomain/ zero/1.0/) applies to the data made available in this article, unless otherwise stated in a credit line to the data. 
carcinoma [4]. The low survival rate in lung cancer has been attributed to an advanced stage and metastases at diagnosis [5]. In addition, drug resistance can also contribute to high mortality [6], with cancer stem cells (CSCs) emerging as a possible instigator in tumor progression, metastasis, and drug resistance [7]. The drugs used most often in first-line chemotherapy for NSCLC are platinum agents such as cisplatin or carboplatin with paclitaxel, gemcitabine, docetaxel, vinorelbine, irinotecan, or pemetrexed [8]. However, acquired resistance or intolerance to these drugs has led to a need for therapies that are more targeted [9].

Drug resistance is attributed to high mortality in several other cancers besides NSCLC, including ovarian, breast, and colorectal cancer [10]. In ovarian cancer, Tie1, which forms part of the tyrosine kinase with immunoglobulin and epidermal growth factor homology domains (TIE) signaling pathway, was found to be involved in platinum-resistance and its high expression was correlated with a significantly poor prognosis [11]. Ishibashi et al.[11] found that the overexpression of Tie1 upregulates nucleotide excision repair to counteract the DNA-adduct damage and subsequent apoptosis caused by cisplatin and other platinum agents. Tie 1 encodes a tyrosine kinase receptor that not only has involvement in drug resistance but may also function in tumorigenesis [12]. In colorectal cancer, Tie1-positive cells were found in populations with CSC characteristics and were able to express the stem cell marker LGR5 [12]. In NSCLC, a female group of patients with adenocarcinoma and high expression of Tie1 had lower overall survival than those with a low expression of Tie1 [13]. In a recent phase II trial with taxane-bevacizumab combination chemotherapy, elevated levels of ANG2 and Tie1 in the blood plasma of patients with metastatic breast cancer were associated with shorter overall survival than baseline levels [14]. During hypoxia and inflammation, Tie1 was found to induce the antagonistic disruptive form of ANG2 $[15,16]$.

Hypoxic conditions are thought to promote drug resistance because the maintenance of CSCs is dependent on low oxygen and hypoxia-inducible factors (HIF) $1 \alpha$ and $2 \alpha$ [17]. HIF- $1 \alpha$ promotes tumorigenesis during hypoxia through the coordination of various transcription factors and subsequent activation of signaling pathways by interacting with hypoxia-response elements (HREs) in promoters [18-20]. Several diseases are believed to result from the dysregulation of hypoxia-related pathways by HIF- $1 \alpha$ through HRE sites [21, 22]. For instance, Twist and BMI1 are thought to influence epithelial cell-mesenchymal transition during renal fibrogenesis when upregulated in hypoxic conditions by HIF- $1 \alpha$ through HRE sites $[21,23]$.
In this study, we investigate the stemness properties of NSCLC cells in response to hypoxia by the expression of hypoxic and stem cell-related markers and whether this influences resistance to cisplatin. In addition, we have identified two sites with consensus HRE binding sequence in the promoter of Tie1. After mutating the HRE sites, we have assessed the involvement of HIF- $1 \alpha$ on the induction of Tie1 in NSCLC cells and the consequences on drug resistance and the stemness of cells.

\section{Materials and methods \\ Cell culture and hypoxic culture conditions}

The NSCLC cell line NCI-H520 was purchased from the American Type Culture Collection (Manassas, VA, USA). The A549, NCI-H460, and NCI-H1975 cell lines were purchased from the Culture Collection of the Chinese Academy of Sciences (Shanghai, China). The NSCLC cell lines were maintained in RPMI 1640 (Thermo Fisher Scientific, Waltham, MA, USA) supplemented with 5\% fetal bovine serum (FBS) and $5 \mathrm{mg} / \mathrm{mL}$ penicillin/streptomycin at $37{ }^{\circ} \mathrm{C}$. Human pulmonary microvascular endothelial cells (HPMEC) were purchased from ScienCell Research Laboratories (San Diego, CA, USA) and maintained in endothelial cell medium (ScienCell) supplemented with $10 \% \mathrm{FBS}$ and $5 \mathrm{mg} / \mathrm{mL}$ penicillin/streptomycin at $37^{\circ} \mathrm{C}$. Cells under normoxic conditions were incubated at $21 \% \mathrm{O}_{2}$ and $5 \% \mathrm{CO}_{2}$. Cells under hypoxic conditions were incubated at $1 \% \mathrm{O}_{2}$ and $5 \% \mathrm{CO}_{2}$.

\section{Western blotting analysis}

To extract proteins for western blot analysis, cells were first lysed in RIPA buffer supplemented with proteinase inhibitors (Pierce Biotechnology, Rockford, IL, USA). Equivalent concentrations of protein measured by a BCA Protein Assay Kit (Thermo Fisher Scientific) were separated by SDS-PAGE and transferred to PVDF membranes (Millipore, Burlington, MA, USA). Membranes were blocked with $5 \%$ non-fat milk for $1 \mathrm{~h}$ and then incubated overnight at $4{ }^{\circ} \mathrm{C}$ with primary antibodies against Tie1 (1:1000, Abcam, Cambridge, UK), BMI-1 (1:1000, Abcam), LGR5 (1:1000; Bioss, Beijing, China), CD44 (1:1000, Cell Signaling Technology, Danvers, MA, USA), HIF-1 $\alpha$ (1:2000, Abcam), $\beta$-actin (1:5000, Abcam), and HA-tag (1:3000, Proteintech, Wuhan, China). Following incubation for $1 \mathrm{~h}$ with HRP-conjugated secondary antibodies (Cell Signaling Technology), immunoreactive bands were visualized with an enhanced chemiluminescence detection system (Thermo Fisher Scientific). The relative intensities of target proteins were quantified by ImageJ software (National Institutes of Health, Bethesda, MD, USA). 


\section{Quantitative reverse transcription PCR (qRT-PCR)}

Total RNA was extracted from cells with Trizol reagent (Invitrogen, Carlsbad, CA, USA). A PrimeScript RT reagent kit (Takara, Kyoto, Japan) was used to synthesize cDNA and an SYBR Green Realtime PCR Premix (Takara) was used with the primer sequences: Tie1, Forward 5'-TTGTGCCCCTGGTCATTTTG-3', Reverse $5^{\prime}$-TCC AGTTCTGAGGCCATGTT-'; GAPDH, Forward 5'-TCA AGAAGGTGGTGAAGCAGG-3', Reverse $5^{\prime}$-TCAAAG GTGGAGGAGTGGGT- $3^{\prime}$. The relative abundance of mRNA was normalized to GAPDH and the $2^{-\Delta \Delta C T}$ method was used to analyze expression levels.

\section{Cell viability assays}

Cells were incubated for $48 \mathrm{~h}$ with a gradient of cisplatin concentrations $(0-32 \mu \mathrm{M}$; Sigma-Aldrich, St. Louis, MO, USA). Cell viability was assessed using a Cell Counting Kit-8 (CCK-8, Dojindo Laboratories, Kumamoto, Japan) according to the manufacturer's instructions. Briefly, cells $\left(\sim 3 \times 10^{3}\right)$ were grown under normoxic or hypoxic conditions in 96-well plates with or without cisplatin for up to $48 \mathrm{~h}$. CCK-8 solution $(10 \mu \mathrm{L})$ was added to each well and after $2 \mathrm{~h}$ incubation at $37{ }^{\circ} \mathrm{C}$, formazan dye was measured at $450 \mathrm{~nm}$ absorbance on a microplate reader (Bio-Rad Laboratories, Hercules, CA, USA) and compared to a standard curve.

\section{Sphere formation assay}

To assess the formation of spheres, cells $\left(1 \times 10^{6}\right.$ per well) preincubated under normoxic or hypoxic conditions were seeded in six-well plates in complete medium. Sphere formation was induced by the addition of $2 \% \mathrm{~B} 27,20 \mathrm{ng} / \mathrm{mL}$ basic fibroblast growth factor, and $20 \mathrm{ng} / \mathrm{mL}$ epidermal growth factor in ultralow attachment six-well plates. After 7 days of incubation, spheres with a diameter greater than $50 \mu \mathrm{M}$ were counted at $\times 40$ magnification.

\section{Cell migration assay}

Cell migration was assessed with the aid of 24-well plate $8-\mathrm{mm}$ pores Transwell inserts (Millipore). Cells $\left(1 \times 10^{4}\right)$ were plated into the top chamber and allowed to migrate into the lower chamber for $24 \mathrm{~h}$. Migrated cells were stained with $0.2 \%$ crystal violet and counted at $\times 40$ magnification.

\section{Immunofluorescence (IF) staining}

Cells were fixed with $4 \%$ paraformaldehyde, washed with PBS, and then blocked with10\% goat serum. They were then incubated with HIF-1 $\alpha$ (1:200, Abcam) antibodies overnight at $4{ }^{\circ} \mathrm{C}$. After incubation, cells were washed twice with $\mathrm{PBS}$ and stained with $\mathrm{Cy} 3$ (red)-conjugated secondary antibody for a further $2 \mathrm{~h}$ at $37{ }^{\circ} \mathrm{C}$. Surplus antibody was removed by washing before obtaining images with an Olympus microscope (Olympus, Tokyo, Japan) at $\times 40$ magnification. Images were captured with a DP50 camera and DP50 software (Olympus).

\section{Plasmid constructs, lentivirus production, and transfection} The stable knockdown of Tie1 was obtained by transfecting A549 and NCI-H1975 cells with lentiviral constructs containing short hairpin RNA (shRNA) sequences. The target sequences $5^{\prime}$-GAGAACCTAGCCTCCAAGATT$3^{\prime}$ of Tie1 shRNA were cloned into the vector GV248 (Genechem, Shanghai, China). A non-silencing scrambled shRNA was used as a negative control (5'-GGC AAGACATACGCTCTCATA-3' ${ }^{\prime}$. Small interfering RNA (siRNA) against human HIF- $1 \alpha$ (target sequences: 5'-GACGATCATGCAGCTACTACA-3') and negative control (5'-GGCACTATCCAACGGTAATCA-3') were synthesized by GenePharma (Shanghai, China) and transfected into A549 and NCI-H1975 cells. To construct a HIF- $1 \alpha$ overexpression vector, the full-length human HIF- $1 \alpha$ was cloned into a pcDNA3-HA vector. The dominant-negative HIF- $1 \alpha$ construct lacking DNA binding and activation domains was generated by PCR and cloned into a pcDNA3-HA vector and transfected into A549 and NCI-H1975 cells. All constructs were confirmed by sequencing and all cells were transfected with vectors or siRNA using Lipofectamine 2000 Reagent (Invitrogen) following the manufacturer's instructions.

\section{Promoter luciferase reporter assays}

The HRE sites in the promoter of Tie1 were assessed using the Dual-Luciferase Reporter Assay System (Promega, Madison, WI, USA). The consensus sequence of the HRE sites in the 1500-bp fragment of the human Tie1 promoter (from -1500 to -1 bp relative to the translation start site) were mutated by substituting CG with AT. The DNA fragment was then cloned into vector pGL3 to generate the construct pGL3-Tie1-Luc. The luciferase reporter vector containing the Tie1 promoter was then transfected into A549 cells together with the pRLTK Renilla luciferase plasmids. Cells were transfected using Lipofectamine 2000 Reagent (Invitrogen) following the manufacturer's instructions. Luciferase activity was measured after $48 \mathrm{~h}$ incubation under hypoxic conditions.

\section{Chromatin immunoprecipitation (ChIP) assay}

Binding between the promoter region of Tie 1 and HIF- $1 \alpha$ was assessed used a ChIP assay kit (Millipore) following the manufacturer's instructions. Briefly, A549 cells were incubated under hypoxic conditions for $24 \mathrm{~h}$ and then 
sonicated to obtain fragmented DNA. Chromatin was immunoprecipitated with anti-HIF-1 $\alpha$ (Novus Biologicals, Littleton, CO, USA) or rabbit IgG (Sigma-Aldrich). The region in the Tie1 promoter containing the HIF- $1 \alpha-$ binding site (5'-CTCGTG-3', from -1032 to -1038 bp relative to the translation start site) was detected and amplified by PCR using the following primers: forward $5^{\prime}$-CATCCCAACCATTCCATTCCG- $3^{\prime}$ and reverse $5^{\prime}$-TTCCCAGAACGGAACAAGACC-3'.

\section{Mouse xenograft model}

All animal experiments were performed in accordance with the guidelines of the Laboratory Animal Ethical Committee at Shanghai Jiao Tong University (Approval number B-2018-010). BALB/c male nude mice (4-6 weeks old) were obtained from Shanghai SLAC Laboratory Animal Co., Ltd (Shanghai, China) and acclimatized for 1 week in specific pathogen-free conditions with sterile food and water. A549 cells stably transfected by scramble or Tie1-shRNA lentiviruses were subcutaneously injected into the right flank of the nude mice. Mice were randomly divided into control (saline) or cisplatin groups $(\mathrm{n}=6,2 \mathrm{mg} / \mathrm{kg}$ body weight delivered by intraperitoneal injection three times a week over 3 weeks). Tumor growth was measured every 5 days. The tumor volume was determined by the formula: Volume $\left(\mathrm{mm}^{3}\right)=$ Length $\times(\text { Width })^{2}$. At the end of the experiment mice were euthanized by cervical decapitation and tumors were excised and weighed. Hematoxylin and eosin (H\&E) staining and immunohistochemistry analysis (IHC) of paraffin sections from xenograft samples was performed using antibodies against Ki67 (1:500, Cell Signaling Technology). For the limiting dilution tumorigenicity assay, each nude mouse was injected with different concentrations of cells $\left(1 \times 10^{6}, 1 \times 10^{5}, 1 \times 10^{4}\right.$, or $1 \times 10^{3}$ cells in $100 \mu$ l DMEM, $\mathrm{n}=5$ ) subcutaneously in the flank. The volume of the tumors was observed and recorded after 5 weeks.

\section{Statistical analysis}

All data were analyzed using the statistical software package GraphPad Prism 7.0 (GraphPad, San Diego, CA, USA). Statistical significance between two groups was determined using the Student's $t$ test, and comparisons among more than two groups were performed using analysis of variance (ANOVA). All in vitro experiments were repeated at least three times independently. Data are presented as the mean \pm standard deviation (SD) unless otherwise stated. $\mathrm{P}<0.05$ was considered significant.

\section{Results}

Increased Tie1 expression in hypoxic lung cancer cells contributes to a reduction in cisplatin sensitivity

To assess the activity of Tie1, we first compared its expression in a pulmonary microvascular endothelial cell line (HPMEC) and NSCLC cell lines (A549, NCI-H460, NCI-H520, and NCI-H1975). Tie1 mRNA and protein levels were significantly higher in HPMECs than in NSCLC cells (Fig. 1a, b). Expression in the A549, NCIH460, and NCI-H1975 cells was at a similar level, with NCI-H1975 slightly higher than the other two cell lines, whereas the expression in NCI-H520 cells was almost undetectable. We selected cell lines A549 and NCIH1975 to investigate whether hypoxia may influence the expression of Tie1. At $24 \mathrm{~h}$, cell viability was significantly lower in both cell lines under hypoxic conditions compared to normoxic conditions, with viability remaining lower for $48 \mathrm{~h}$ during hypoxia (Fig. 1c). After $12 \mathrm{~h}$ under hypoxic conditions, the expression of Tie1 significantly increased in both cell lines and continued to increase until a highly significant level was reached (Fig. 1d, e). These results indicate that under normoxic conditions, Tie1 expression is lower in NSCLC cells than in normal dividing cells but under hypoxic conditions, such as that found in tumor microenvironments, the expression of Tie1 significantly increases. To analyze whether the high expression of Tie1 could influence drug resistance, A549 and NCI-H1975 cells transfected with scramble or Tie1-shRNA lentiviruses were treated with cisplatin under normoxic or hypoxic conditions for $48 \mathrm{~h}$ (Fig. 1f, g). Initially, cells cultured under hypoxia were resistant to cisplatin. However, it was clear that the cells with Tie1 silenced had a significantly decreased cell viability and were more sensitive to cisplatin, under hypoxic conditions. Overall, these results indicate that hypoxia increases drug resistance in NSCLC cells and that Tie1 expression promotes a more resistant phenotype.

\section{Tie1 knockdown impairs hypoxia-induced cancer stemness properties}

Having established that Tie1 knockdown reduces cell viability under hypoxia we investigated whether hypoxiainduced cell stemness properties are impaired. A sphereforming assay indicated that cell stemness was reduced in A549 and NCI-H1975 cells with Tie1 knockdown after incubation for $48 \mathrm{~h}$ in hypoxic conditions (Fig. 2a). Hypoxic conditions induced a higher level of sphere formation than normoxic conditions. We also determined the expression levels of stemness-related markers by western blot analysis. The expression levels of LGR5, BMI-1, and CD44 were increased with hypoxia but LGR5 and BMI-1 levels reduced significantly and CD44 expression decreased slightly when Tiel was knocked down 


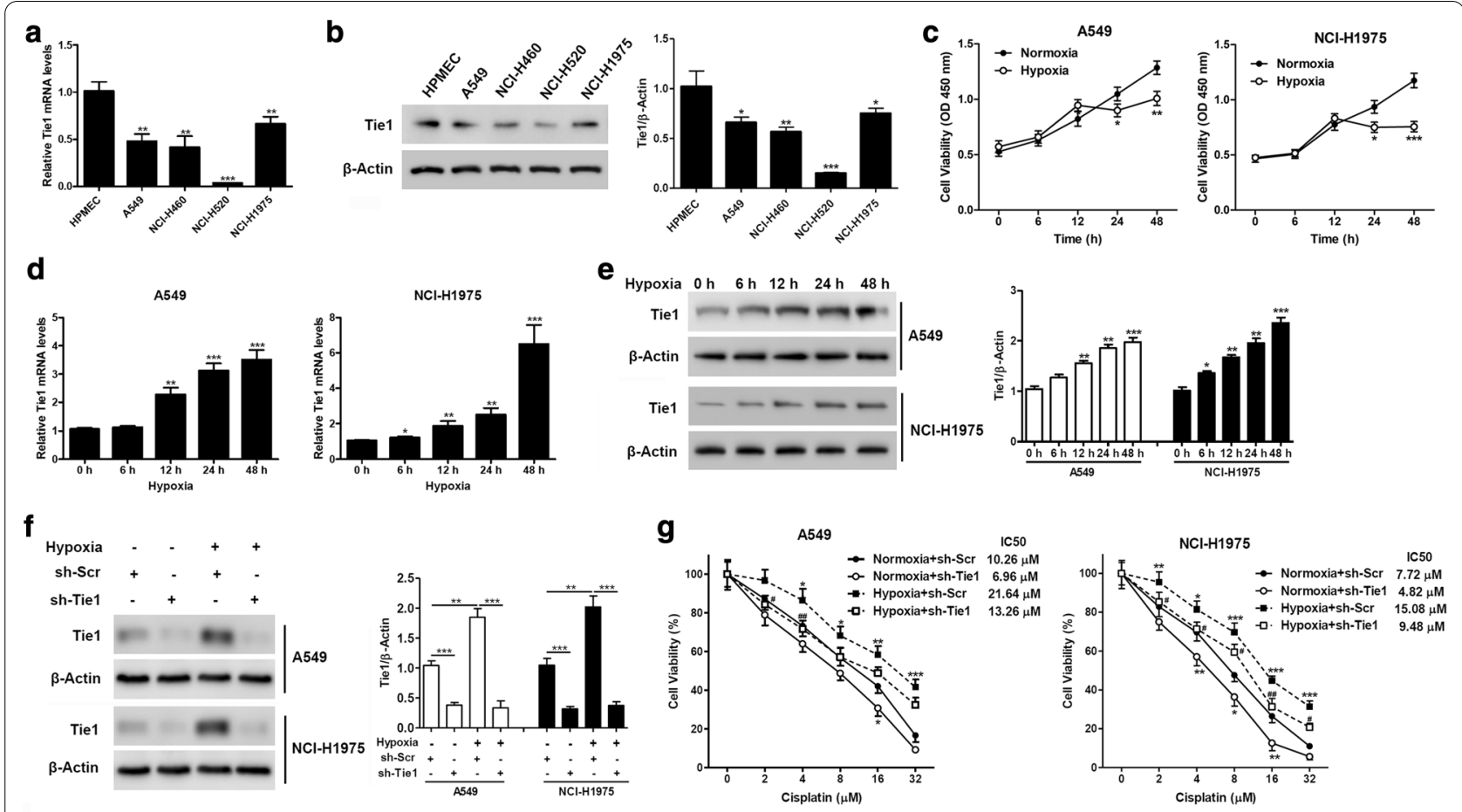

Fig. 1 Hypoxia-enhanced Tie1 expression in human lung cancer cells contributes to reduced cisplatin sensitivity. a and b, Tie1 mRNA levels (a) and protein levels (b) in human pulmonary microvascular endothelial cells (HPMECs) and human NSCLC cell lines were detected by qRT-PCR and western blot, respectively. ${ }^{*} P<0.05,{ }^{*} P<0.01,{ }^{* * *} P<0.001$. Relative protein levels quantified by ImageJ and normalized to $\beta$-actin. $(n=3)$. c Cell viability of A549 cells, and NCl-H1975 cells exposed to hypoxia for 0, 6, 12, 24, and 48 h. d and e, A549 cells, and NCl-H1975 cells were exposed to hypoxia for $\mathbf{0 , 6}, 12,24$, and $48 \mathrm{~h}$. mRNA levels (d) and protein levels (e) were detected by qRT-PCR and western blotting, respectively. Relative protein levels quantified by ImageJ and normalized to $\beta$-actin. ${ }^{*} P<0.05$, ${ }^{* *} P<0.01$, ${ }^{* * *} P<0.001$. $(n=3)$. f A549 cells and NCI-H1975 cells stably transfected by scramble or Tie1-shRNA lentiviruses were incubated under hypoxic conditions for $48 \mathrm{~h}$. Proteins were analyzed using western blotting. Relative protein levels quantified by ImageJ and normalized to $\beta$-actin. ${ }^{* *} \mathrm{P}<0.01,{ }^{* *} \mathrm{P}<0.001$. $(n=3)$. g A549 cells and NCl-H1975 cells stably transfected by scramble or Tie1-shRNA lentiviruses were treated with cisplatin under normoxic or hypoxic conditions for $48 \mathrm{~h}$. Cell viability was assessed by CCK-8 assays. ${ }^{* P}<0.05$, ${ }^{*} \mathrm{P}<0.01,{ }^{* *} \mathrm{P}<0.001$ vs Normoxia + sh-Scr, ${ }^{\#} \mathrm{P}<0.05$, ${ }^{\# \#} \mathrm{P}<0.01$ vs Hypoxia + sh-Scr, using two-way ANOVA followed by Bonferroni post hoc test. $(n=3)$

(Fig. 2b). This indicates that a number of pathways could be involved in the response to hypoxia and the stemness of cells. Moreover, hypoxia increases the migration of NSCLC cells and Tie1 knockdown can reduce the number of migratory cells under normoxic and hypoxic conditions (Fig. 2c). Therefore, Tie1 expression can influence the stemness of NSCLC cells, especially under hypoxic conditions.

\section{Tie1 knockdown enhances the anti-tumor effect of cisplatin in vivo}

In a murine xenograft model, A549 cells stably transfected by scramble or Tie1-shRNA lentiviruses were subcutaneously injected into the right flank of nude mice. Mice received either cisplatin or saline control (Fig. 3a, b). Tie1 knockdown was found to enhance the anti-tumor effect of cisplatin in vivo as demonstrated by the reduced volume of tumors. The expression levels of stemnessrelated genes were also reduced when Tie1 was knocked down in tumors (Fig. 3c). Immunohistochemical staining of the cell division marker Ki67 in xenograft tumor tissues confirmed that cells become more sensitive to cisplatin and cell division is reduced when the expression of Tie1 is lowered (Fig. 3d). To establish the role of Tie1 in cancer stem cell, we performed limiting dilution tumorigenicity assay, further found that A549 cells transfected with sh-Tie1 formed smaller subcutaneous tumors (Fig. 3e). The results in the mouse xenograft model support the in vitro findings that Tie1 promotes the stemness of cells and reduces the sensitivity to cisplatin.

\section{Hypoxia-mediated induction of Tie 1 is HIF-1a-dependent}

To characterize the involvement of hypoxia in the induction of Tie1, we measured the level of HIF-1 $\alpha$ expression in A549 cells under hypoxic conditions. After $24 \mathrm{~h}$, HIF- $1 \alpha$ reaches a significantly higher level of expression than in normoxic conditions (Fig. 4a). The elevation of HIF- $1 \alpha$ transcription factor levels and its translocation 

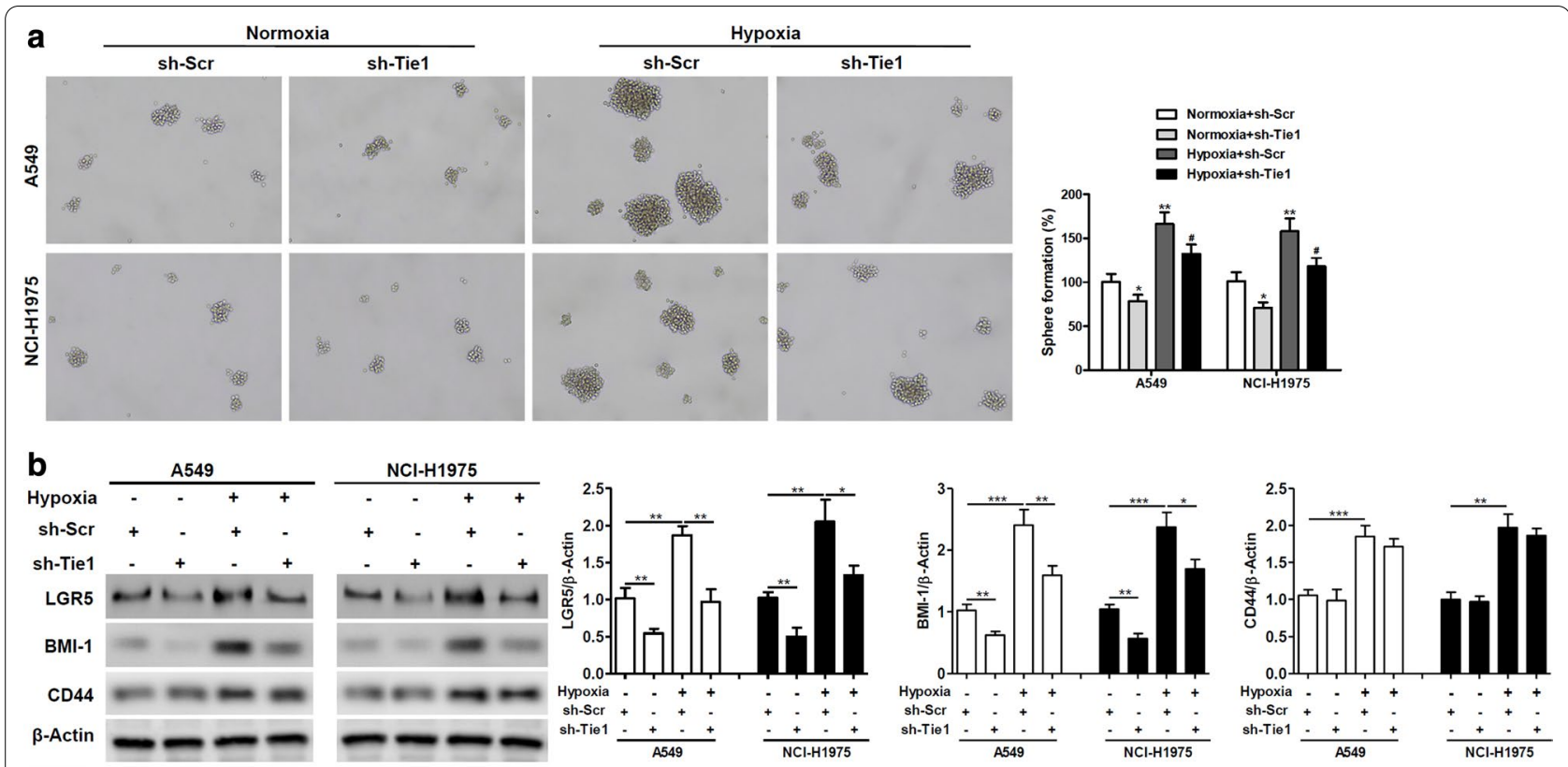

C
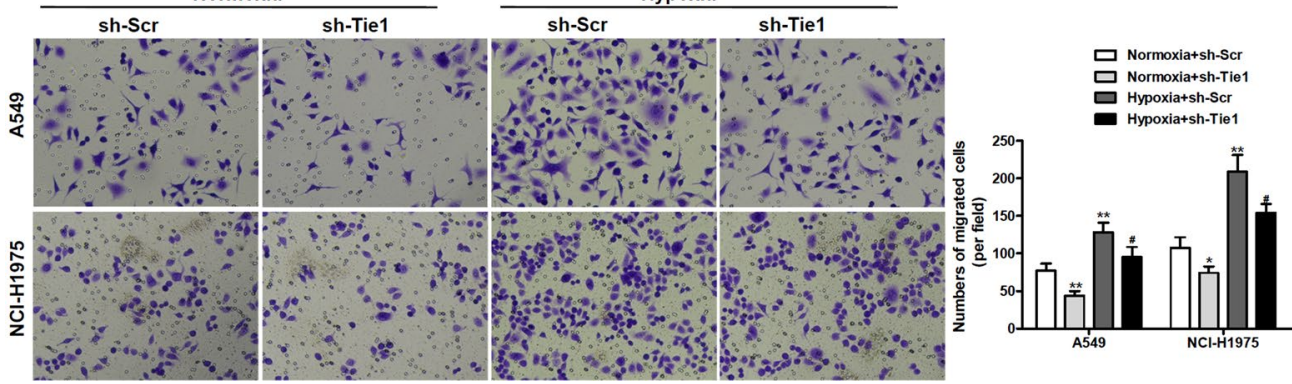

Fig. 2 Tie1 knockdown constrains hypoxia-induced cancer stemness properties. a Representative image of spheres after treatment. A549 cells and $\mathrm{NCl}-\mathrm{H} 1975$ cells transfected with scramble or Tie1-shRNA lentiviruses were exposed to normoxic or hypoxic conditions for $48 \mathrm{~h}$. The ability of the cells to form spheres was investigated by a sphere-forming assay. The percentage of sphere formation (diameter $>50 \mu \mathrm{m}$ ) is shown in the bar graph. ${ }^{*} \mathrm{P}<0.05,{ }^{* *} \mathrm{P}<0.01$ vs Normoxia + sh-Scr, ${ }^{\# P}<0.05$ vs Hypoxia + sh-Scr. $(n=3)$. $\mathbf{b}$ The expression levels of stemness-related genes were determined by western blot analysis. Relative protein levels quantified by ImageJ and normalized to $\beta$-actin. ${ }^{*} P<0.05,{ }^{* *} P<0.01,{ }^{* * *} P<0.001$. ( $(n=3)$. c Migration ability of A549 and NCl-H1975 cells transfected by scramble or Tie1-shRNA lentiviruses incubated under normoxic or hypoxic conditions for $48 \mathrm{~h}$ were evaluated by Transwell assays. The numbers of migrated cells are shown in the bar graph. ${ }^{*} P<0.05,{ }^{* *} P<0.01$ vs Normoxia + sh-Scr, ${ }^{\#} P<0.05$ vs Hypoxia + sh-Scr. $(n=3)$

to the nucleus by hypoxia are demonstrated by immunofluorescence staining (Fig. 4b). To validate if the levels of Tie 1 are influenced by HIF- $1 \alpha$, we measured the level of both proteins under hypoxia. We found that the expression of both proteins was increased by hypoxia but the level of Tie1 is also reduced when HIF-1 $\alpha$ is downregulated (Fig. 4c). Moreover, when A549 cells were transfected with a dominant-negative version of HIF- $1 \alpha$, containing mutated binding and activation sites, Tie1 expression under hypoxia was reduced compared to cells transfected with wild-type (wt) HIF-1 $\alpha$ (Fig. 4d). Taken together, these results indicate that the hypoxia-mediated induction of Tie1 expression is HIF-1 $\alpha$-dependent.

\section{HIF-1 a regulates Tie1 expression through direct binding to its promoter}

To understand the regulation of Tie1 further, in silico analysis was performed and we identified two sites that shared homology with the HIF- $1 \alpha$-binding consensus sequence $\mathrm{BDCGTV}(\mathrm{B}=\mathrm{C} / \mathrm{T} / \mathrm{G}, \mathrm{D}=\mathrm{A} / \mathrm{G} / \mathrm{T}$, $\mathrm{V}=\mathrm{G} / \mathrm{C} / \mathrm{A}$ ). The promoter of Tie1 contains two predicted HIF- $1 \alpha$ binding sites HRE1 and HRE2. We mutated both sites and conducted a luciferase activity assay to establish whether the sites could be involved in the activation by HIF- $1 \alpha$ (Fig. 5a). Luciferase activity was significantly increased under hypoxia, wt-HIF- $1 \alpha$ significantly increased the basal and hypoxia-induced 


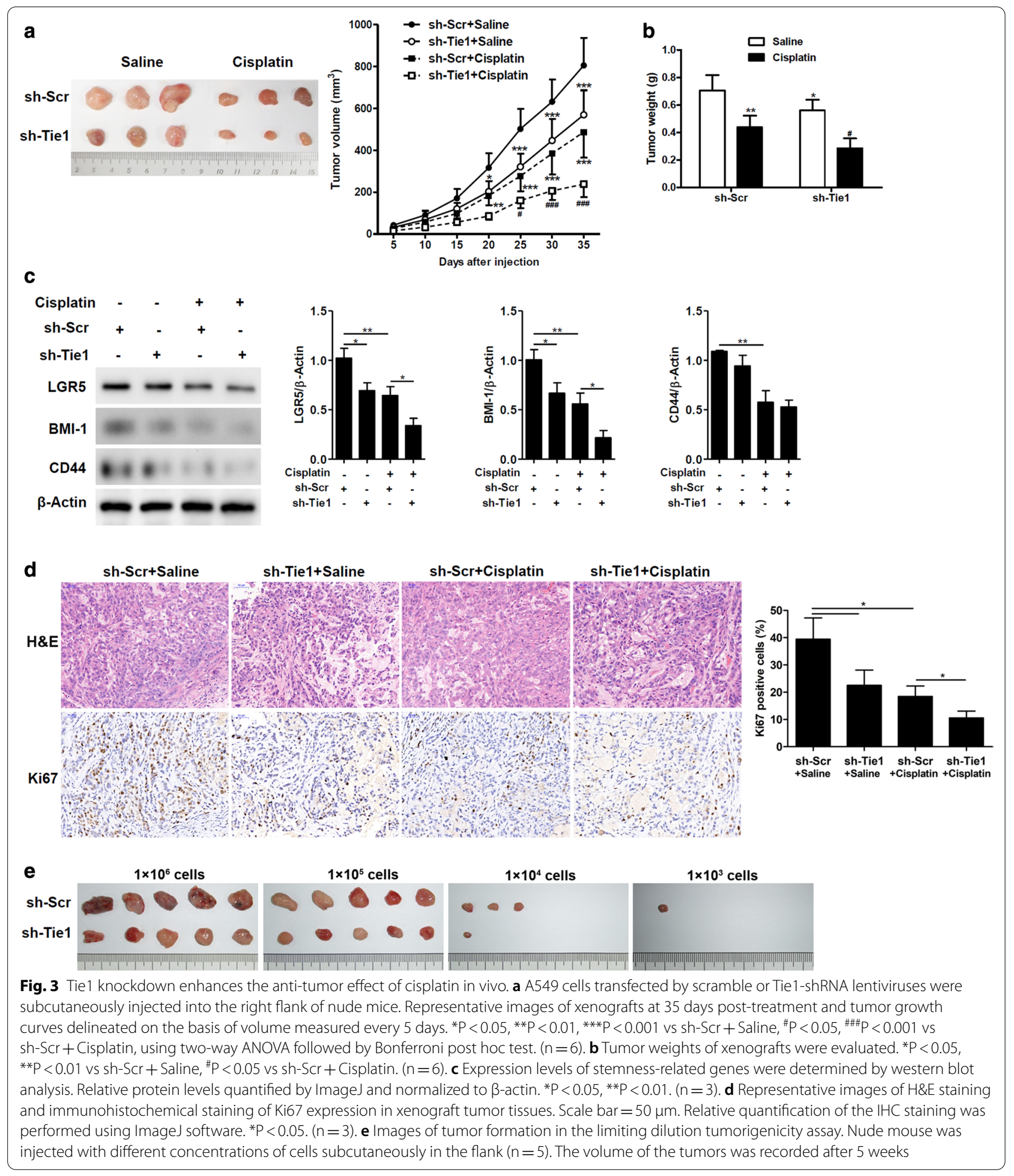

elevation of luciferase activity, but HIF- $1 \alpha$-with a dominant negative mutation effectively inhibited it (Fig. 5b). In A549 cells transfected with pGL3-Tie1-Luc or HRE mutant constructs, the wt promoter induced a higher level of luciferase activity than the promoter with either HRE1 and/or HRE2 mutations under hypoxia (Fig. 5c). ChIP analysis was used to confirm the direct binding of HIF- $1 \alpha$ to the Tie1 promoter DNA (Fig. $5 \mathrm{~d}$ ). These 


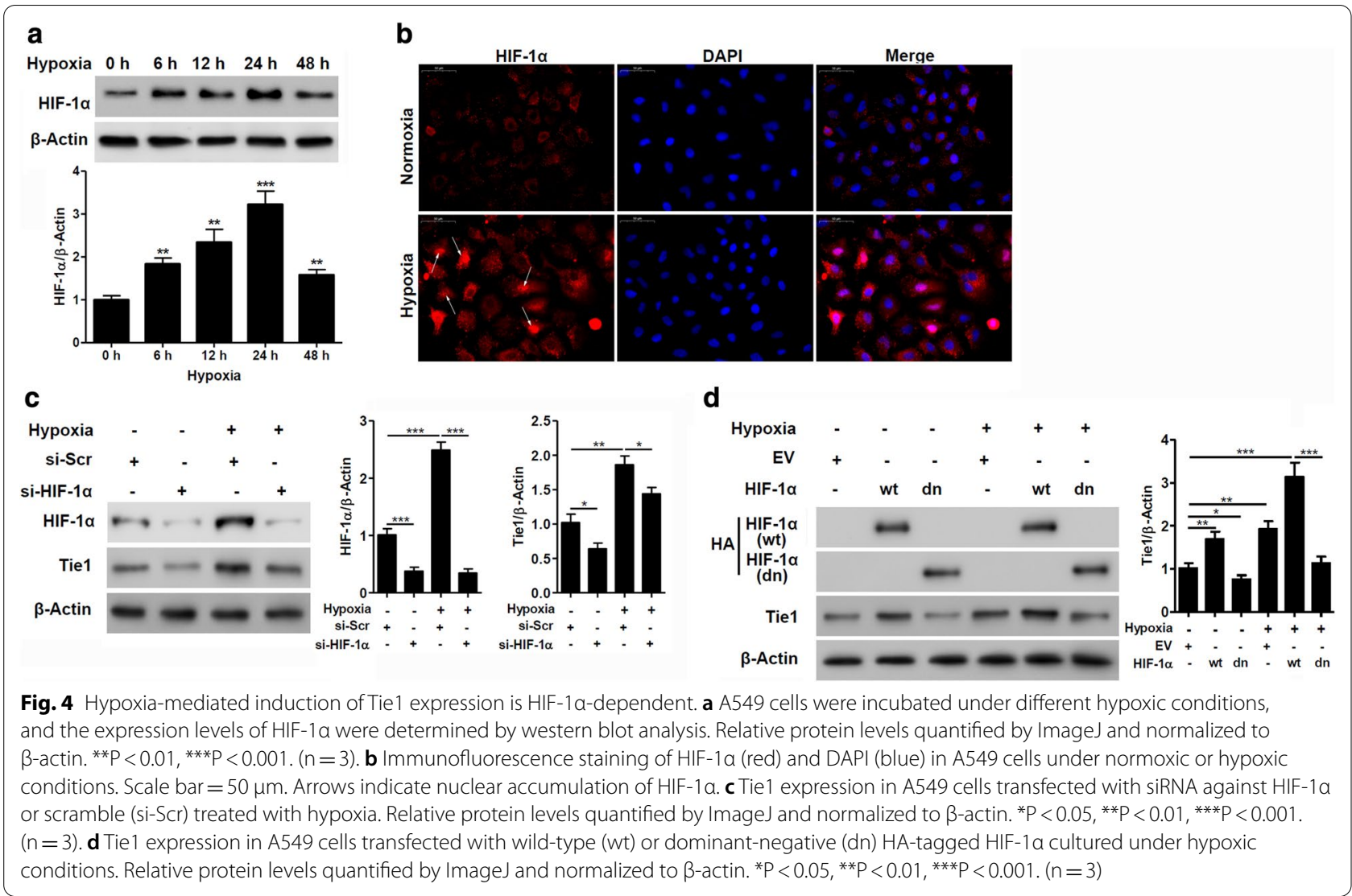

findings indicate that both HRE sites are required for the induction of Tie 1 by HIF- $1 \alpha$.

\section{HIF-1 a controls the stemness of NSCLC cell by regulating Tie 1 expression}

Finally, we assessed whether HIF- $1 \alpha$ could potentially control NSCLC cell stemness under hypoxia by regulating Tie1 expression. Tie1 expression is increased in A549 cells overexpressing HIF-1 $\alpha$ (Fig. 6a). In addition, the formation of spheres seems to be predominately influenced by the expression of HIF-1 $\alpha$. Downregulating Tie1 reduces the number of spheres formed when HIF-1 $\alpha$ is overexpressed but stemness remains significantly higher than the control (Fig. 6b). Similar results were found for the expression of cell division markers LGR5, BMI-1, and CD44 was stronger in cells overexpressing HIF- $1 \alpha$. However, the increase observed in the cells overexpressing HIF- $1 \alpha$ decreased significantly in the absence of Tie1 (Fig. 6c). The migratory ability of A549 cells was also elevated in cells overexpressing HIF- $1 \alpha$ in the presence of Tie1 (Fig. 6d). Although the number of migratory cells was reduced when Tie1 is downregulated, migration was still significantly higher than in control cells. From these results, we can conclude that HIF- $1 \alpha$ controls the stemness of cells by regulating Tie1 expression in NSCLC.

\section{Discussion}

Improving the outcome in NSCLC remains a challenge with growing evidence suggesting that hypoxia promotes the stemness of cells and resistance to therapy [24-27]. Moreover, a close relationship exists between the expression of HIF-1 $\alpha$ and metastasis in NSCLC [28]. To clarify the mechanisms involved in hypoxia-related drug resistance and stemness and to identify potential therapeutic targets, we measured the impact of HIF- $1 \alpha$ on the induction of Tie1 in NSCLC cells and the effects on drug resistance and stemness in vitro and in vivo. We found that when Tie1 was silenced there was a consequential increase in the sensitivity of NSCLC cells to cisplatin. High expression of Tie1 in NSCLC cells resistant to paclitaxel was discovered in an earlier large-scale microarray study [29]. The authors of this study identified several receptor tyrosine-protein kinases (RTK) in the drug resistance of NSCLC cells, including ERRB4, KIT, and Tie1, and suggested that the inhibition of RTKs may sensitize cancer cells to paclitaxel. Interestingly, they also found that NSCLC cell lines respond differently to 

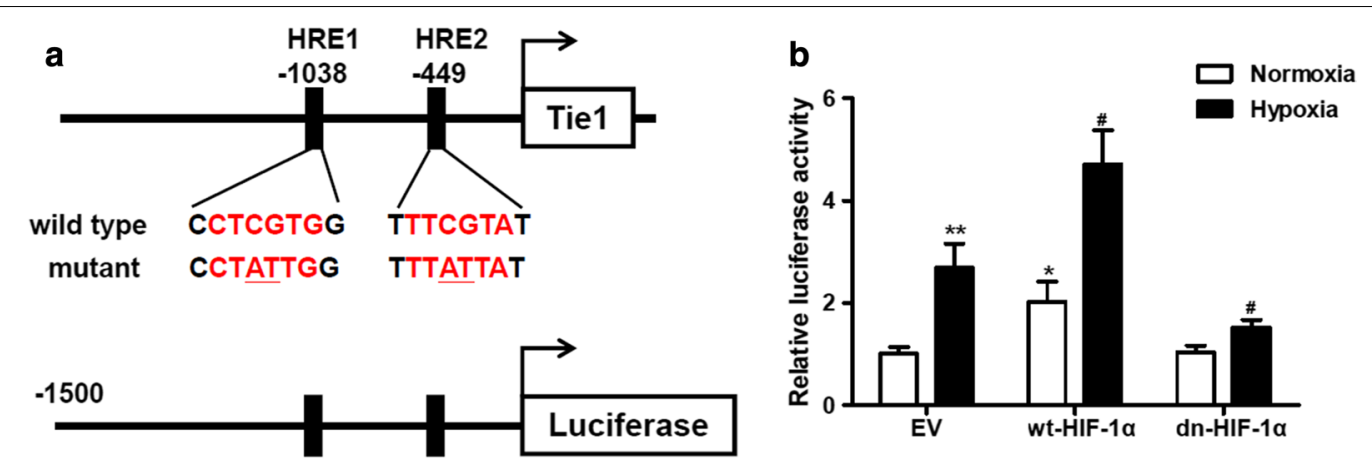

\section{c}

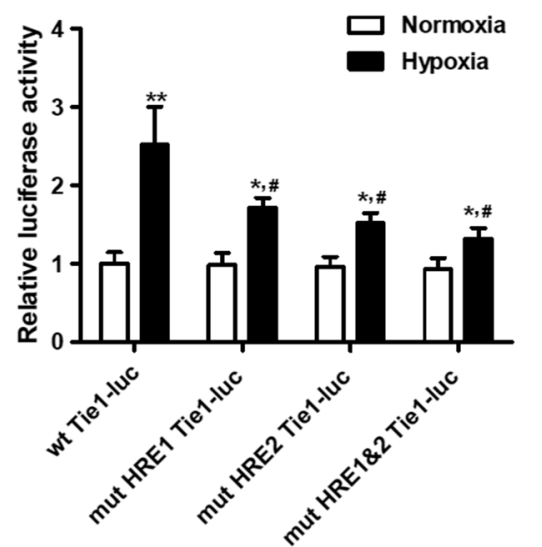

d

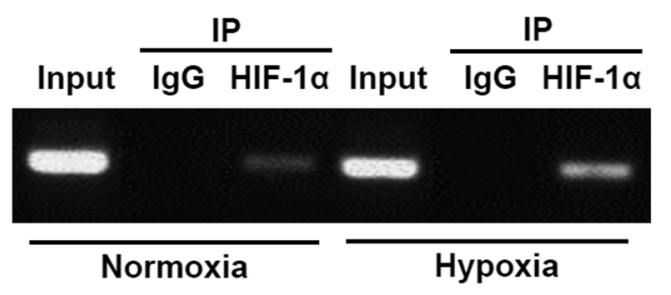

Fig. 5 HIF-1a directly binds to the Tie1 promoter. a Diagram showing the two predicted HIF-1a binding sites on the Tie1 promoter and mutagenesis information of each HRE site. b A549 cells were co-transfected with pGL3-Tie1-Luc and wild-type (wt) or dominant-negative (dn) HIF-1 a followed by hypoxic incubation, and luciferase activity was measured at $48 \mathrm{~h}$ after hypoxia. ${ }^{* P}<0.05$, ${ }^{* *} \mathrm{P}<0.01 \mathrm{vs}$ Normoxia + EV, $\mathrm{P}<0.05$ vs Hypoxia + EV. $(n=3)$. c A549 cells were transfected with pGL3-Tie1-Luc or HRE mutant constructs containing the HRE1 mutation and/or HRE2 mutation, followed by hypoxic incubation, and luciferase activity was measured at $48 \mathrm{~h}$ after hypoxia treatment. ${ }^{*} \mathrm{P}<0.05$, ${ }^{* *} \mathrm{P}<0.01$ vs Normoxia + wt Tie1-Luc, ${ }^{\#} \mathrm{P}<0.05$ vs Hypoxia + wt Tie1-Luc. $(n=3)$. d A549 cells were incubated under hypoxic or normoxic conditions for 24 h. Cell lysate was collected for the ChIP analysis of HIF-1a binding to Tie1 promoter DNA

different chemotherapeutic agents and the expression of Tie1 was relatively uninfluenced by docetaxel.

In the present study, we found that the expression of Tie1 was significantly elevated in response to hypoxia and that the down-regulation of Tie1 by shRNA could render cells more sensitive to cisplatin and reduce the stemness characteristics of cells. The involvement of Tie1 in the stemness of cancer cells has also been noted in another study [30]. La Porta et al. [30] studied Tie1 in tumor progression and found that the deletion of Tie1 in a mouse metastasis model prevented the extravasation of tumor cells into the lungs and reduced metastatic foci. In our study, hypoxia gave rise to increased drug resistance and an elevated level of genetic markers associated with stemness. Recent research supports the role of hypoxia in the stemness of cancer cells [31, 32]. In particular, HIF-1 $\alpha$ has been found to promote the stemness of cancer cells through the regulation of several pathways, including PI3K/Akt/mTOR [26], Wnt/ $\beta$-catenin [33], and
Notch [34] signaling. We used immunofluorescence to demonstrate that hypoxia influenced the expression of LGR5. Moreover, the levels of LGR5 are also influenced by PI3K/Akt/mTOR [35], Wnt/ $\beta$-catenin [36], and Notch signaling [37], suggesting that HIF-1 $\alpha$ and hypoxia could also be involved in the regulation of LGR5. In a xenograft murine model of tumorigenesis using A549 NSCLC cells transfected with Tie1-shRNA, we found that the levels of Ki67 were reduced and that tumors were more sensitive to cisplatin. In a previous study, Gong et al. found that the suppression of Krüppel-like factors 5 (KLF5) could inhibit cisplatin resistance induced by the overexpression of HIF- $1 \alpha$ by inactivating the PI3K/Akt/mTOR pathway in NSCLC cells [26]. Whether Tie1 is influenced by the $\mathrm{PI} 3 \mathrm{~K} / \mathrm{Akt} / \mathrm{mTOR}$ pathway has yet to be established.

In this study, we found that the induction of Tie1 in hypoxia is HIF-1 $\alpha$-dependent. By identifying two sites in the promoter of Tie1 with HRE binding consensus sequence $(\mathrm{BDCGTV}, \mathrm{B}=\mathrm{C} / \mathrm{T} / \mathrm{G}, \mathrm{D}=\mathrm{A} / \mathrm{G} / \mathrm{T}, \mathrm{V}=\mathrm{G} / \mathrm{C} / \mathrm{A}$ ) 


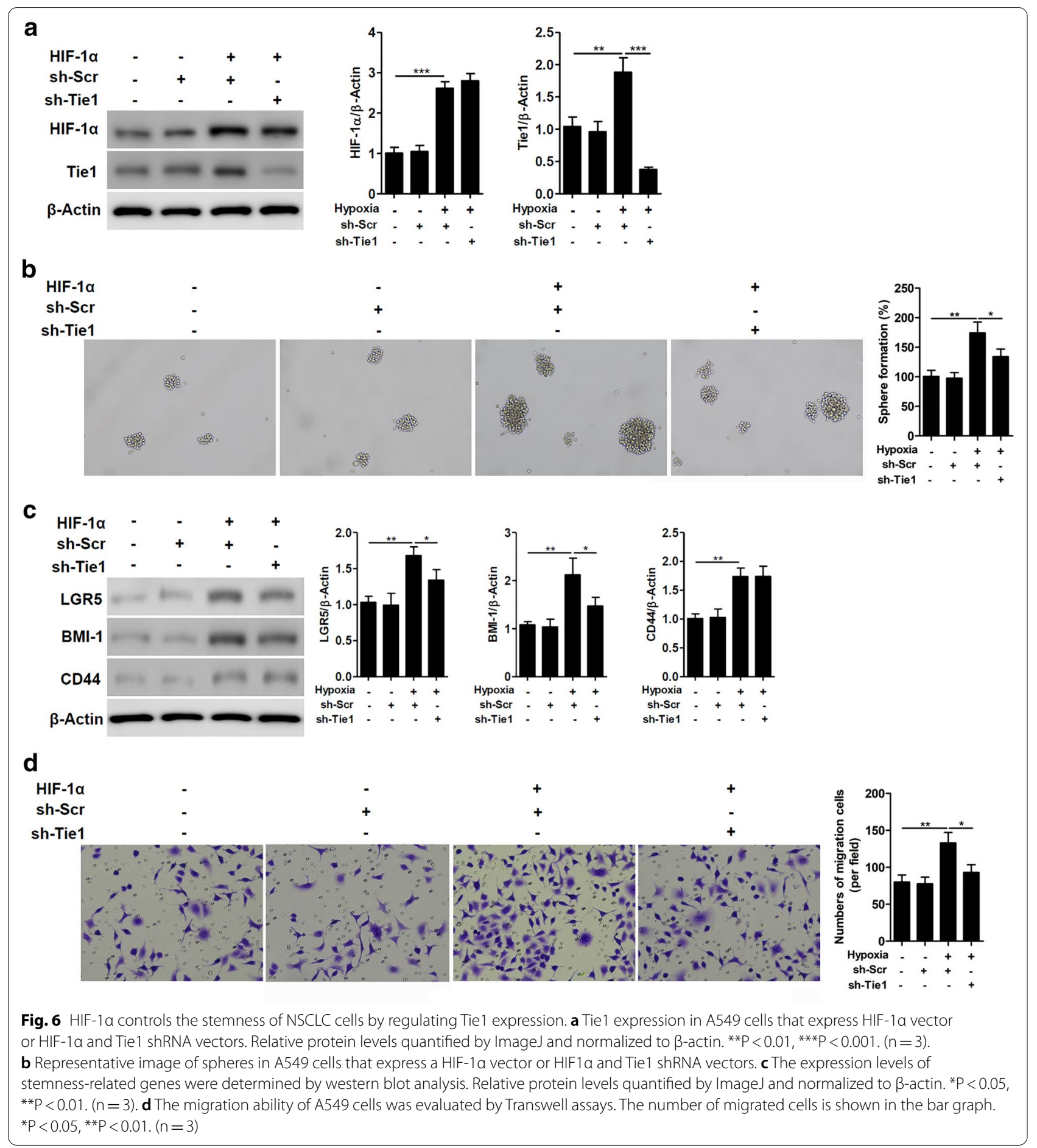

[21], we were able to conduct luciferase assays and discovered that HIF- $1 \alpha$ could upregulate Tie 1 through interacting with both of these sites. ChIP analysis confirmed that HIF- $1 \alpha$ could bind to the HRE sites in the promoter of Tie1. KLF5 is also known to co-immunoprecipitate with HIF- $1 \alpha$ under hypoxic conditions in NSCLC [38].
HIF- $1 \alpha$ has been recognized as a regulator of drug resistance in various drugs [39-41]. Under normoxic conditions, HIF- $1 \alpha$ is located in the cytoplasm where it binds to von Hippel Lindau tumor suppressor (VHL) through the hydroxylation of proline residues and is subsequently degraded by the ubiquitin-proteasome system [42]. 
Under hypoxia, HIF-1 $\alpha$ does not bind to VHL and is not degraded but it translocates to the nucleus where it forms a stable HIF-1 heterodimer with HIF-1 $\beta$ and acts as a transcription factor with genes controlled by HREs. Our results show an accumulation of undegraded HIF- $1 \alpha$ in the cytoplasm of NSCLC cells under hypoxia. Therefore, in the hypoxic tumor microenvironment, genes that are involved in mechanisms related to stemness and drug resistance, such as Tie1 and KLF5, are artificially upregulated.

\section{Conclusion}

Our results further support evidence that a hypoxic tumor microenvironment can increase the development of drug resistance and promote stemness characteristics in NSCLC. Interfering with the expression of Tie1 was able to increase sensitivity to cisplatin and reduce the migration and sphere-forming properties in cells. This study highlights the importance of counteracting hypoxia and proposes that Tie1 could be a potential target for increasing drug sensitivity and reducing stemness in the management of NSCLC.

\section{Abbreviations}

NSCLC: Non-small cell lung carcinoma; HREs: Hypoxia-response elements; TIE: Tyrosine kinase with immunoglobulin and epidermal growth factor homology domains; HIF: Hypoxia-inducible factors.

\section{Acknowledgements}

Not applicable.

\section{Authors' contributions}

$C L, N Y$, and $Z C$ performed the experiment, acquisition, and analysis of data, and drafting the article; NX, QS, ZW, JL performed the experiments and collected the data; MS, ZW contributed to the study design, analysis, and interpretation of data; All authors read and approved the final manuscript.

\section{Funding}

This study was supported by the Key Program of Shanghai Science and Technology Association (No. 16411952600), Shanghai Nature Science Foundation (19ZR1432600), Shanghai Key Specialty Construction Project (No. ZK2019A02), Shanghai Municipal Key Clinical Specialty (No. shslczdzk06002, No. shslczdzk07002), and the Shanghai Municipal Health Bureau (201640125).

\section{Availability of data and materials \\ The data used to support the findings of this study are available from the cor- responding author upon request.}

\section{Ethics approval and consent to participate}

All animal experiments were performed in accordance with the guidelines of the Laboratory Animal Ethical Committee at Shanghai Jiao Tong University.

\section{Consent for publication}

Not applicable.

\section{Competing interests}

The authors declare that they have no competing interests.

\section{Author details}

1 Department of Radiology, Ruijin Hospital Luwan Branch, Shanghai Jiao Tong University School of Medicine, No. 149 Chongqing South Road, Shanghai 200025, China. ${ }^{2}$ Department of Interventional Radiology, Tongren
Hospital, Shanghai Jiao Tong University School of Medicine, 1111 Xianxia Road, Shanghai 200336, China. ${ }^{3}$ Department of Interventional Radiology, Ruijin Hospital, Shanghai Jiao Tong University School of Medicine, No. 197 Ruijin Er Road, Shanghai 200000, China.

Received: 5 August 2020 Accepted: 21 December 2020

Published online: 18 January 2021

\section{References}

1. Siegel RL, Miller KD, Jemal A. Cancer statistics, 2020. CA Cancer J Clin. 2020;70(1):7-30.

2. Barta JA, Powell CA, Wisnivesky JP. Global epidemiology of lung cancer. Ann Glob Health. 2019;85(1):8,

3. Travis WD, Brambilla E, Nicholson AG, Yatabe Y, Austin JHM, Beasley MB, Chirieac LR, Dacic S, Duhig E, Flieder DB, et al. The 2015 World Health Organization classification of lung tumors: impact of genetic, clinical and radiologic advances since the 2004 classification. J Thorac Oncol. 2015;10(9):1243-60

4. Cheng TY, Cramb SM, Baade PD, Youlden DR, Nwogu C, Reid ME. The international epidemiology of lung cancer: latest trends, disparities, and tumor characteristics. J Thorac Oncol. 2016;11(10):1653-71.

5. Woodard GA, Jones KD, Jablons DM. Lung cancer staging and prognosis. Cancer Treat Res. 2016;170:47-75.

6. Liu WJ, Du Y, Wen R, Yang M, Xu J. Drug resistance to targeted therapeutic strategies in non-small cell lung cancer. Pharmacol Ther. 2020:206:107438.

7. Leon G, MacDonagh L, Finn SP, Cuffe S, Barr MP. Cancer stem cells in drug resistant lung cancer: targeting cell surface markers and signaling pathways. Pharmacol Ther. 2016;158:71-90.

8. Zappa C, Mousa SA. Non-small cell lung cancer: current treatment and future advances. Transl Lung Cancer Res. 2016;5(3):288-300.

9. Terlizzi M, Colarusso C, Pinto A, Sorrentino R. Drug resistance in non-small cell lung Cancer (NSCLC): impact of genetic and non-genetic alterations on therapeutic regimen and responsiveness. Pharmacol Ther. 2019;202:140-8.

10. Costea T, Vlad OC, Miclea LC, Ganea C, Szollosi J, Mocanu MM. Alleviation of multidrug resistance by flavonoid and non-flavonoid compounds in breast, lung, colorectal and prostate cancer. Int J Mol Sci. 2020;21(2):401.

11. Ishibashi M, Toyoshima M, Zhang X, Hasegawa-Minato J, Shigeta S, Usui T, Kemp CJ, Grandori C, Kitatani K, Yaegashi N. Tyrosine kinase receptor TIE-1 mediates platinum resistance by promoting nucleotide excision repair in ovarian cancer. Sci Rep. 2018;8(1):13207.

12. Torigata M, Yamakawa D, Takakura N. Elevated expression of Tie1 is accompanied by acquisition of cancer stemness properties in colorectal cancer. Cancer Med. 2017;6(6):1378-88.

13. Sun R, Bao MY, Long X, Yuan Y, Wu MM, Li X, Bao JK. Metabolic gene NR4A1 as a potential therapeutic target for non-smoking female nonsmall cell lung cancer patients. Thorac Cancer. 2019;10(4):715-27.

14. Tiainen L, Korhonen EA, Leppanen VM, Luukkaala T, Hamalainen M, Tanner M, Lahdenpera O, Vihinen P, Jukkola A, Karihtala P, et al. High baseline Tie1 level predicts poor survival in metastatic breast cancer. BMC Cancer. 2019;19(1):732.

15. Kelly BD, Hackett SF, Hirota K, Oshima Y, Cai Z, Berg-Dixon S, Rowan A, Yan Z, Campochiaro PA, Semenza GL. Cell type-specific regulation of angiogenic growth factor gene expression and induction of angiogenesis in nonischemic tissue by a constitutively active form of hypoxia-inducible factor 1. Circ Res. 2003;93(11):1074-81.

16. Akwii RG, Sajib MS, Zahra FT, Mikelis CM. Role of angiopoietin-2 in vascular physiology and pathophysiology. Cells. 2019;8(5):471.

17. Schoning JP, Monteiro M, Gu W. Drug resistance and cancer stem cells: the shared but distinct roles of hypoxia-inducible factors HIF1alpha and HIF2alpha. Clin Exp Pharmacol Physiol. 2017:44(2):153-61.

18. Balamurugan K. HIF-1 at the crossroads of hypoxia, inflammation, and cancer. Int J Cancer. 2016;138(5):1058-66.

19. O'Rourke JF, Dachs GU, Gleadle JM, Maxwell PH, Pugh CW, Stratford IJ, Wood SM, Ratcliffe PJ. Hypoxia response elements. Oncol Res. 1997;9(6-7):327-32 
20. Albadari N, Deng S, Li W. The transcriptional factors HIF-1 and HIF-2 and their novel inhibitors in cancer therapy. Expert Opin Drug Discov. 2019;14(7):667-82.

21. Sun S, Ning $X$, Zhang Y, Lu Y, Nie Y, Han S, Liu L, Du R, Xia L, He L, et al. Hypoxia-inducible factor-1alpha induces Twist expression in tubular epithelial cells subjected to hypoxia, leading to epithelial-to-mesenchymal transition. Kidney Int. 2009;75(12):1278-87.

22. Miyazaki K, Kawamoto T, Tanimoto K, Nishiyama M, Honda H, Kato Y. Identification of functional hypoxia response elements in the promoter region of the DEC1 and DEC2 genes. J Biol Chem. 2002;277(49):47014-21.

23. Du R, Xia L, Ning X, Liu L, Sun W, Huang C, Wang H, Sun S. Hypoxiainduced Bmi1 promotes renal tubular epithelial cell-mesenchymal transition and renal fibrosis via PI3K/Akt signal. Mol Biol Cell. 2014;25(17):2650-9

24. Salem A, Asselin MC, Reymen B, Jackson A, Lambin P, West CML, O'Connor JPB, Faivre-Finn C. Targeting hypoxia to improve non-small cell lung cancer outcome. J Natl Cancer Inst. 2018;110(1):14-30.

25. Lu Y, Liu Y, Oeck S, Glazer PM. Hypoxia Promotes Resistance to EGFR Inhibition in NSCLC Cells via the Histone Demethylases, LSD1 and PLU-1. Mol Cancer Res. 2018;16(10):1458-69.

26. Gong T, Cui L, Wang H, Han N. Knockdown of KLF5 suppresses hypoxiainduced resistance to cisplatin in NSCLC cells by regulating HIF-1adependent glycolysis through inactivation of the PI3K/Akt/mTOR pathway. J Transl Med. 2018;16(1):164.

27. Wang J, Tian L, Khan MN, Zhang L, Chen Q, Zhao Y, Yan Q, Fu L, Liu J. Ginsenoside Rg3 sensitizes hypoxic lung cancer cells to cisplatin via blocking of NF-kB mediated epithelial-mesenchymal transition and stemness. Cancer Lett. 2018;415:73-85

28. Pezzuto A, Perrone G, Orlando N, Citarella F, Ciccozzi M, Scarlata S, Tonini G. A close relationship between HIF-1a expression and bone metastases in advanced NSCLC, a retrospective analysis. Oncotarget. 2019;10(66):7071-9.

29. Che $C L$, Zhang YM, Zhang HH, Sang YL, Lu B, Dong FS, Zhang LJ, Lv FZ. DNA microarray reveals different pathways responding to paclitaxel and docetaxel in non-small cell lung cancer cell line. Int J Clin Exp Pathol. 2013;6(8):1538-48.

30. La Porta S, Roth L, Singhal M, Mogler C, Spegg C, Schieb B, Qu X, Adams $\mathrm{RH}$, Baldwin HS, Savant S, et al. Endothelial Tie1-mediated angiogenesis and vascular abnormalization promote tumor progression and metastasis. J Clin Investig. 2018;128(2):834-45.

31. Abou Khouzam R, Goutham HV, Zaarour RF, Chamseddine AN, Francis A, Buart S, Terry S, Chouaib S. Integrating tumor hypoxic stress in novel and more adaptable strategies for cancer immunotherapy. Semin Cancer Biol. 2020;65:140-54.

32. Najafi M, Farhood B, Mortezaee K, Kharazinejad E, Majidpoor J, Ahadi R. Hypoxia in solid tumors: a key promoter of cancer stem cell (CSC) resistance. J Cancer Res Clin Oncol. 2020;146(1):19-31.

33. Lv Z, Liu RD, Chen XQ, Wang B, Li LF, Guo YS, Chen XJ, Ren XQ. HIF1alpha promotes the stemness of oesophageal squamous cell carcinoma by activating the Wnt/betacatenin pathway. Oncol Rep. 2019;42(2):726-34.

34. Moriyama H, Moriyama M, Ozawa T, Tsuruta D, Iguchi T, Tamada S, Nakatani T, Nakagawa K, Hayakawa T. Notch signaling enhances stemness by regulating metabolic pathways through modifying p53, NF-kB, and HIF-1a. Stem Cells Dev. 2018;27(13):935-47.

35. Chen J, Shao R, Li F, Monteiro M, Liu JP, Xu ZP, Gu W. PI3K Akt/mTOR pathway dual inhibitor BEZ235 suppresses the stemness of colon cancer stem cells. Clin Exp Pharmacol Physiol. 2015;42(12):1317-26.

36. Zhou JY, Huang DG, Zhu M, Gao CQ, Yan HC, Li XG, Wang XQ. Wnt/ßcatenin-mediated heat exposure inhibits intestinal epithelial cell proliferation and stem cell expansion through endoplasmic reticulum stress. J Cell Physiol. 2020;235(7-8):5613-27.

37. Wu A, Yu B, Zhang $K, X u Z$, Wu D, He J, Luo J, Luo Y, Yu J, Zheng P, et al. Transmissible gastroenteritis virus targets Paneth cells to inhibit the self-renewal and differentiation of Lgr5 intestinal stem cells via Notch signaling. Cell Death Dis. 2020;11(1):40.

38. Li X, Liu X, Xu Y, Liu J, Xie M, Ni W, Chen S. KLF5 promotes hypoxiainduced survival and inhibits apoptosis in non-small cell lung cancer cells via HIF-1alpha. Int J Oncol. 2014;45(4):1507-14.

39. Masoud GN, Li W. HIF-1 a pathway: role, regulation and intervention for cancer therapy. Acta Pharm Sin B. 2015;5(5):378-89.

40. Lv Y, Zhao S, Han J, Zheng L, Yang Z, Zhao L. Hypoxia-inducible factor1 alpha induces multidrug resistance protein in colon cancer. Onco Targets Ther. 2015;8:1941-8.

41. Tong Y, Li QG, Xing TY, Zhang M, Zhang JJ, Xia Q. HIF1 regulates WSB-1 expression to promote hypoxia-induced chemoresistance in hepatocellular carcinoma cells. FEBS Lett. 2013;587(16):2530-5.

42. Rankin EB, Giaccia AJ. Hypoxic control of metastasis. Science. 2016:352(6282):175-80

\section{Publisher's Note}

Springer Nature remains neutral with regard to jurisdictional claims in published maps and institutional affiliations.
Ready to submit your research? Choose BMC and benefit from:

- fast, convenient online submission

- thorough peer review by experienced researchers in your field

- rapid publication on acceptance

- support for research data, including large and complex data types

- gold Open Access which fosters wider collaboration and increased citations

- maximum visibility for your research: over $100 \mathrm{M}$ website views per year

At BMC, research is always in progress.

Learn more biomedcentral.com/submissions 